\title{
Qumran e as identidades plurais no judaísmo antigo
}

\author{
Jonas Machado*
}

\section{Resumo}

Este artigo se insere nos recentes estudos sobre a identidade e sua relação com a religião no mundo antigo, especialmente no judaísmo antigo, e notadamente nos manuscritos do Mar Morto. As evidências dos manuscritos de Qumran, agora publicados in totum, apontam um judaísmo de identidade fluída, multifacetada, diferente do que vinha sendo assumido até então.

Palavras chave: Identidade, Judaísmo antigo, Qumran.

\section{Qumran and Plural identities in the Ancient judaism}

Abstract

This article is included in recent studies on Identity and its relation to religion in the Ancient world, especially in Ancient Judaism, and notably in the Dead Sea Scrolls. Evidence from Qumran manuscripts, now published in totum, points to a fluid, multifaceted judaism of identity diferent from what had been assumed so far.

Key words: Identity, Ancient judaism, Qumran.

\section{Qumran y las identidades plurales en el judaísmo antiguo}

\section{Resumen}

Este artículo se inserta en los recientes estudios sobre la identidad y su relación con la religión en el mundo antiguo, especialmente en el antiguo judaísmo, y también en los manuscritos del Mar Muerto. Las evidencias de los manuscritos de Qumran, ahora publicados in totum, apuntan un judaísmo de identidad fluida, multifacética, diferente de lo que venía siendo asumido hasta entonces.

Palabras clave: Identidad, Judaísmo Antiguo, Qumran.

\footnotetext{
* Faculdade Teológica Batista de São Paulo. Email: machadojs21@terra.com.br
} 


\section{Introdução}

O propósito deste artigo é esboçar a relevância do estudo da(s) identidade(s) no(s) judaísmo(s) antigo(s) ${ }^{1}$, tendo em vista especialmente o novo momento proporcionado pelas descobertas dos manuscritos de Qumran, ou manuscritos do Mar Morto ${ }^{2}$, e mais recentemente pela publicação de todos estes documentos, agora disponíveis para o público acadêmico, e até mesmo para o público em geral ${ }^{3}$.

A descoberta desse material a partir de 1947 causou espanto e alvoroço, que têm perdurado décadas. Com o acesso a todo esse material, ficou mais clara a visão sobre o que realmente eles são, isto é, manuscritos e fragmentos que são parte de um conjunto bem maior. Isso quer dizer que agora ficou mais clara a dimensão tanto dos limites quanto das possibilidades de abordagem desse material para a melhor compreensão do mundo antigo.

Dito isto, vale ressaltar que estamos mais com aqueles que veem nesses textos um material útil para a história do judaísmo antigo (GARCÍAMARTÍNEZ, 1995, p.11; SILVA, 2016) do que com aqueles que entenderam que tal material não contribui para a história das origens judaicas porque não são do gênero histórico (VERMÈS, 1997, p.28). Este é um tipo de debate que continua intrigando os pesquisadores, que divergem sobre de que maneira fontes, como a Bíblia Hebraica e os manuscritos de Qumran, poderiam ser úteis para construir uma história de Israel cientificamente plausível ${ }^{4}$.

1 Na antiguidade, há uma identidade idealizada no emprego invariável do termo "judaísmo" no singular que contrasta com as evidências textuais de um judaísmo multifacetado, conforme está explicado no decorrer deste artigo. Por isto, alguns preferem inclusive falar de “judaísmos" e, consequentemente, de "identidades", no plural. Estes termos são empregados geralmente no singular nesse artigo, mas sem perder estas concepções de vista.

2 Embora o conjunto todo seja denominado "manuscritos do Deserto da Judeia", conforme a coleção DJD (Discoveries in the Judaean Desert), "manuscritos de Qumran”, ou "manuscritos do Mar Morto" são as nomenclaturas mais conhecidas, visto que as margens do Mar Morto, e especialmente os arredores de Qumran, foram os locais da maior parte das descobertas.

3 Para a batalha das publicações desde a descoberta até recentemente, veja o resumo em Machado; Funari (2012). Schuller (2019) menciona a alegria de chegar aos setenta anos após a primeira descoberta com todos os textos publicados, as batalhas que decorreram, e os desafios que se seguem.

4 Trobolowsky (2018), por exemplo, fala do recente debate entre as posições "maximalista" e "minimalista" de estudiosos que, respectivamente, consideram o texto bíblico válido como fonte para a história de Israel, e os que entendem que tais fontes devem ser procuradas fora da Bíblia Hebraica, uma vez que esta não é adequada como fonte histórica. A crítica pós-moderna, diz Trobolowski, se dirige principalmente contra o conceito de construir 
No caso do judaísmo antigo propriamente, uma das grandes contribuições desses manuscritos foi em relação à natureza deste seguimento humano, suas facetas, seus coloridos, que antes já tinham sido destacados por alguns autores, mas que agora ficaram mais na superfície, revelando um judaísmo do Segundo Templo bem mais colorido e multifacetado do que se imaginava antes. Este é o foco principal desse ensaio.

Segue, portanto, um esboço sobre o estudo da identidade, particularmente associado ao tema da religião, e mais particularmente ainda associado ao judaísmo antigo, âmbito ao qual pertencem os manuscritos do Mar Morto, descobertos nos arredores de Qumran.

\section{O estudo da identidade}

A situação atual das relações sociais é muito mais ampla e complexa do que jamais se imaginou. De modo bem econômico, podemos dizer que a aproximação das várias sociedades promovida pelo desenvolvimento em larga escala da comunicação e transporte, notoriamente por instrumento dos avanços tecnológicos e eletrônicos, com destaque para a mídia virtual, em poucos anos colocou as relações sociais em um mundo completamente novo. O encontro perplexo com a imensa pluralidade social de nosso planeta, naturalmente faz com que aflorem perguntas sobre a compreensão de si mesmo e do outro, frente a essa nova realidade.

Mas perguntar pela identidade passa, entre outras coisas, por questionar as origens. Aqui, portanto, se insere a pesquisa da identidade no mundo antigo. Para compreendermos melhor a nossa própria identidade, quem nós somos, que sociedade nós caracterizamos, precisamos buscar os parâmetros que marcaram sua origem.

Esta questão das origens ficou ainda mais em evidência diante das declarações do atual governo brasileiro em termos de resgatar os valores judaico-cristãos do Brasil que, supõe-se, estão na sua origem ${ }^{5}$. Naturalmente,

\footnotetext{
"a" história de Israel válida universalmente, admitindo em oposição o conceito plural de "histórias", com muitos potenciais de significado. Ele exemplifica com a teoria do "panisraeliteísmo" que propõe que os conteúdos das narrativas da Bíblia Hebraica resultam da apropriação por parte de Judá (Reino do Sul) da identidade de Israel (Reino do Norte), após a queda deste em 722 aEC. A teoria é que todas estas narrativas foram inventadas para justificar a sobrevivência de Judá, e que, antes da queda de Israel, o povo de Judá não se considerava etnicamente israelita.

5 Logo no início da apresentação assinada pelo Senhor Presidente da República, Jair Messias Bolsonaro, feita para o texto denominado "Mensagem ao Congresso Nacional",
} 
este não é tema a ser desenvolvido num artigo como este, mas envolve a pergunta sobre quais, realmente, são tais raízes, e de que modo as tradições judaico-cristãs se relacionam com o povo brasileiro. Daí também se torna mais relevante ainda perguntar pela natureza da identidade do judaísmo antigo, bem como do cristianismo das origens.

Nesse sentido, a pesquisa da identidade no mundo antigo, particularmente no período de transição marcado pelo chamado judaísmo tardio e inícios do cristianismo, se reveste de peculiar importância, justamente porque nossa sociedade ocidental é tida como originária do judaísmo e cristianismo, e historicamente judaico-cristã. Em meio aos diversos matizes que se possa destacar quanto a tais origens de nossa sociedade ocidental, o judaísmo antigo e o cristianismo primitivo tiveram papel decisivo.

No caminho reverso, entretanto, quem estuda sobre identidade na antiguidade só pode fazê-lo a partir do presente, de sua própria realidade e identidade. Pois, como o mundo acadêmico de hoje tende a reconhecer cada vez mais, inclusive ao tentar propor novas metodologias, ninguém faz essa viagem ao passado na condição de tabula rasa, como um pesquisador "neutro" à busca da verdade. Recentemente, destaca-se a tendência, como na sociologia do conhecimento, de reconhecer que todo conhecimento e pensamento se desenvolve desde o início debaixo de certa configuração social. Nisto estão inclusas tanto as fontes analisadas como a própria condição de quem pesquisa ${ }^{6}$.

Existem ainda posições mais radicais que desejam enfatizar que identidade não deve ser uma questão de buscar origens no passado, mas tão somente de construir o futuro, um "vir a ser" contínuo ${ }^{7}$. Tal crítica

há a seguinte afirmação: "O Brasil resistiu a décadas de uma operação cultural e política destinada a destruir a essência mais singela e solidária de nosso povo, representada nos valores da civilização judaico-cristã". O texto pode ser acessado em www.casacivil.gov. br/central-de-conteúdos/downloads/mensagem-ao-congresso-2019/@@download/file/ mensagem-ao-congresso-2019.pdf. Extraído em 24/05/2019.

6 Uma abordagem recente desse tema com alguns desdobramentos por uma perspectiva brasileira arqueológica e histórica pode ser encontrada nas obras Funari (2005, 2007, 2008, 2009). Uma abordagem da sociologia do conhecimento está em Bertelli (1974). Robbins (1996) propõe o que chama de "Criticismo Sócio-Retórico", que procura fazer interagir o mundo da fonte antiga analisada com o mundo do pesquisador atual, isto é, com métodos recentes de abordagem. A preocupação com a influência dos pressupostos do pesquisador para o estudo do judaísmo antigo está em destaque em Stone (2011).

Em inglês, é bastante popularizada a frase atribuída a George Bernard Shaw: "Life isn't about finding yourself. Life is about creating yourf", o que, numa tradução livre, seria "a vida não diz respeito a encontrar a si mesmo. A vida diz respeito a criar a si mesmo". 
desconstrutiva fala em "mapear" o passado ao invés de "traçar" o passado, no sentido de substituir uma abordagem temporal e genealógica por outra espacial e localizada (SILBERSTEIN, 2000, p.1-4).

Essa posição crítica acima quer nos alertar para o fato de que a busca por identidade no passado, no sentido genealógico, geralmente pressupõe tratar o tema de modo apenas positivo, ignorando as implicações de poder na própria reconstrução da suposta identidade. Não podemos deixar de reconhecer que há efeitos de poder sobre a construção de identidade. Essa crítica, entretanto, não alcançou força suficiente para estancar ou redirecionar a pesquisa geral sobre identidade em termos de mapeamento do passado. Mas ela deve ser levada em conta para registrar que a busca pelo passado se faz inevitavelmente a partir do presente, com todas as implicações disso, inclusive a decorrência de resultados sempre maquiados de alguma forma.

A própria conceituação de "identidade" é algo recente, uma palavra que se destacou primeiro em inglês, "identity", a partir do século XVI (LIEU, 2002, p.301). Esta constatação é importante porque, por si só, ela nos alerta para o fato de que falar de identidade na antiguidade é falar de uma abstração sempre sujeita a anacronismos.

Mas, ao passo que o estudo sobre identidade hoje recebe peculiar destaque e tem dimensões complexas que atravessam inúmeras disciplinas e se reporta a questões de múltipla intersecção de raças, classes e gênero, alguns vinham reclamando que a questão religiosa permanecia negligenciada (APPIAH; GATES, 1995, p.1,4).

\section{Identidade e Religião}

A busca acadêmica por uma melhor compreensão da identidade de maneira mais bem fundamentada sempre passará pela religião e vice-versa. Ainda que existam os que não concordam que a religião seja intrínseca ao ser humano, vendo-a apenas como efeito de outras causas, pelo menos é preciso reconhecer que as preocupações com o tema da identidade acabam sempre passando pelas questões de fé.

No passado, a religião era tema apenas para teólogos que a investigavam "de dentro", mas a partir principalmente dos inícios do século XX o cenário mudou. As Ciências Sociais surgiram já reconhecendo o valor do estudo antropológico e sociológico da religião, pois, 
Em síntese, a coesão, e (sic) as tensões sociais e as manifestações públicas de religiosidade proclamadas por meio da fé, do lazer e dos costumes alimentares, contribuem para ratificar tradições, revigorar os sentidos de pertencimento, explicar, fortalecer e contestar hierarquias além de fortalecer as intricadas identidades nacionais, regionais, étnicas e religiosas, reveladoras de aspectos da vida social e do patrimônio cultural de inúmeras comunidades (PELEGRINI; FUNARI, 2008, p.99).

Sendo assim, é necessário enfatizar que a motivação para estudos sobre o tema da identidade tem relações com a presença constante deste assunto em pesquisas recentes. Naturalmente, como já dito, esta motivação está relacionada com a situação do mundo atual ${ }^{8}$. Tal interesse pelo tema da identidade em relação à religião também está associado ao fato de que a concepção de identidade passou por uma profunda mudança nos últimos anos, em decorrência das marcantes transformações sociais hodiernas.

Para resumir, há hoje maneiras plurais de ver praticamente cada uma das antigas questões entendidas como essenciais, as quais geralmente eram vistas de modo unívoco. As mudanças na concepção de família, na relação entre homem e mulher, nas relações destes no que tange ao trabalho, enfim, nas várias relações sociais no mundo globalizado, têm profundas implicações para a identidade e avassaladoras consequências para a religião?.

Por isso, diversas publicações no campo das Ciências Humanas exibem preocupação com o tema da identidade e também com o tema da religião, embora não necessariamente associados. As mudanças, grosso modo citadas acima, deram nova relevância à velha pergunta "quem sou eu/somos

8 Por exemplo, os interesses, bem como as preocupações e as perguntas sobre esse tema, como os mencionados a seguir estão, explícita ou implicitamente, presentes nos vários capítulos das obras de história e arqueologia organizadas por Funari (2005, 2009), e Rago e Funari (2008).

9 Como exemplo dessas consequências para a religião, entre muitas outras, da perspectiva teológica pode ser mencionada a mudança do dogma milenar sustentado pela igreja católica pelo menos desde Cipriano no século III EC, extra eclesiam nulla salus (fora da igreja não há salvação), para concepções inclusivistas bem mais moderadas a partir do Concílio Vaticano II, realizado na primeira metade dos anos 1960, conforme os documentos Ad Gentes, Lumen Gentium, e Nostra Aetate, que admitem ação divina salvadora mesmo em outras religiões e invertem o sentido do dogma - isto é, agora "fora da igreja há salvação" - ainda que mantenham, ao mesmo tempo, a superioridade cristã (VIER, 1968). Embora as razões para tal mudança possam ser bem complexas, a realidade agora mais visível das pluralidades contribuiu decisivamente para essa inversão do dogma, como os teólogos geralmente têm admitido (KÜNG, 1976, p.72ss). 
nós?", que agora recebe respostas equívocas e instáveis, num processo de construção, desconstrução e reconstrução.

Essa situação também levantou perguntas quanto ao modo como vinha sendo entendida a identidade no que se refere à antiguidade. Em decorrência de questionamentos contra métodos elitistas prevalecentes na análise das sociedades antigas, agora está na agenda uma busca por novos caminhos de natureza mais plural e ampla para o estudo da identidade em sociedades primevas ${ }^{10}$.

Uma maneira de exemplificar tais novos caminhos metodológicos é a "Hermenêutica da Suspeita" e a "Identidade Narrativa", ambas ligadas a Paul Ricoeur (1969, 1985, 1990), aqui apenas esboçadas conforme os interesses desse ensaio.

A Hermenêutica da Suspeita, entre outras coisas, fornece referenciais para uma interpretação que leva em conta as pluralidades, sem ilusões quanto a assumir uma hermenêutica universal de um só sentido para os textos, onde o objeto de interpretação deixa de ser tão somente uma escrita ou um texto. Agora há todo um conjunto maior de signos a serem considerados. É necessário ir além do patente texto escrito e buscar o que está latente ${ }^{11}$ no texto, nas entre linhas.

A Identidade Narrativa, por sua vez, reconhece tanto a implicação de estabilidade e permanência intrínseca na concepção de identidade, como também as inevitáveis transformações que são próprias do existir temporal.

Considerando essa linha de reflexão, a concepção antiga de identidade passa por estruturas simbólicas de várias naturezas, inclusive a religiosa, nas quais há uma correlação ambígua entre a realidade vivida ${ }^{12}$ e o discurso social explícito apresentado. Por um lado, há uma afirmação de identidade estática e única, que faz parte do imaginário social, político e religioso de uma determinada sociedade, que convive, por outro lado, com evidências de uma identidade em constante mudança marcada por pluralidades.

10 A História recente considera que fontes não são apenas "textos", geralmente produzidos por elites letradas, mas tudo o que o ser humano produziu ou produz (veja GRILLO; FUNARI, 2010).

11 Tal latência, nessa concepção, está relacionada ao psiquismo inconsciente, vontade de poder, que compõem o ser social a ser revelado e decifrado por trás de certas manhas do sentido consciente que está patente no texto.

12 Este artigo não entra no debate sobre a relação dos textos com a experiência religiosa per se, isto é, até que ponto os textos podem representar experiências religiosas reais, praticadas ritualmente. Esse importante tema tem recebido maior destaque ao longo das publicações que discutem a natureza da experiência religiosa em Qumran (HIMMELFARB, 1993; ALEXANDER, 2006). 
Há evidência, por exemplo, de que antigas biografias greco-romanas não apresentavam um desenvolvimento da personalidade humana do tipo "do ventre ao túmulo" porque consideravam a que o caráter de um indivíduo é estático e não se desenvolve com o tempo, algo que é hoje seriamente questionado de diversos pontos de vista (WITHERINGTON, 2006, p.175).

Outro exemplo é a sociedade judaica do período conhecido como do Segundo Templo, que é flagrada pelas evidências textuais e arqueológicas como sendo caracterizada por múltiplas faces, a ponto de alguns autores terem concluído que só é possível falar de “judaísmos”, no plural (LIEU, 2002).

Portanto, as evidências levantadas atualmente levaram a considerar o “judaísmo comum” como uma ilusão recente, que deve ser agora moderada pela concepção de um judaísmo que não era monolítico no sentido de ter uma uniformidade normativa, embora não fosse também tão diverso a ponto de ter sido um caos completamente amorfo (CHARLESWORTH, 1985, p.xxix).

Em consonância com isso, Jones (2005, p.29) lembra a prática de ignorar o material não judaico encontrado em sítios supostamente judaicos como evidência de presença de outros grupos ou assimilação, por causa de uma concepção estanque de identidade por parte do arqueólogo. Em outras palavras, o arqueólogo, neste caso, pressupôs que a identidade judaica teria permanecido homogênea em diferentes períodos e lugares antes de examinar as evidências.

Ao mesmo tempo, porém, o termo "judaísmos", no plural, não foi empregado pelos antigos, e não fazia parte do imaginário dos indivíduos daquela própria sociedade, visto que invariavelmente o termo foi empregado no singular.

Isso significa dizer que os antigos usaram uma linguagem no singular que revela um imaginário de identidade unificada e estática, ao mesmo tempo em que deixaram em suas fontes, sejam textos ou artefatos, as evidências de uma realidade identitária plural em transformação, nas quais o conceito de "gregos versus bárbaros" ou "judeus versus gentios", ou seja, "eu/nós versus o(s) outro(s)" representam um imaginário identitário simplista (LIEU, 2002, p.311-312).

Tais concepções são válidas simultaneamente para questões étnicas (judeus, gregos, bárbaros) e para questões religiosas (judaísmo, cristianismo) - questões que, na verdade, sempre estão entrelaçadas.

Assim, o estudo da identidade com destaque para a religião se torna importante perante os anseios atuais de revisão das abordagens tidas como 
elitistas e rígidas. Conforme Guarinello (2009, p.152) (13 $^{3}$ o imaginário de identidade única e rígida é próprio das elites que tendem a uma unificação progressiva política e cultural, ao passo que tal unificação, ou tentativa dela, no caso das massas populares, se deu no âmbito das crenças religiosas.

Entretanto, esse imaginário de identidade única das elites (estas criadoras das fontes textuais da história que negligenciam a vida rural e os pobres), exemplificado por Guarinello na oficialização do cristianismo como religião do Império Romano, é traído pelos rastros de sincretismo deixados nas fontes religiosas. Tais rastros evidenciam não somente crenças plurais e difusas, mas também e, concomitantemente, identidades fluídas e em construção.

Essa situação atual do estudo dos temas envolvidos permite que sejam desenvolvidas pesquisas sobre identidade e religião a partir de novas premissas e, consequentemente, com novos resultados. Isso tudo tem implicações para o estudo do judaísmo antigo, incluindo os famosos manuscritos do Mar Morto, de Qumran.

\section{Identidade judaica no mundo antigo}

Visto que constituímos uma sociedade marcada pelas tradições judaico-cristãs quanto às suas origens, como já mencionado, é importante ter em mente as possíveis implicações disso para a relação "nós" e "eles" quando se trata do judaísmo e emergente cristianismo em meio aos povos antigos. Embora alguns, como também já mencionado, vinham reclamando da negligência das pesquisas no campo religioso da identidade, o estudo deste tema levando em conta este período tem sido objeto de considerável pesquisa nas últimas décadas (NICKELSBURG, 2011, p.262).

Nos textos que representam as tradições mais antigas de Israel que constam na Bíblia Hebraica, os mandamentos e proibições que denotam a rígida separação entre Israel e os demais povos já estão entremeados por histórias como de Tamar (Gênesis 38) e do livro de Rute, nas quais as relações com povos estrangeiros são tratadas naturalmente. As duras proibições de relações com estrangeiros são temperadas, por assim dizer, com histórias que relatam tais relações, inclusive que resultam compor a genealogia de personagens tão importantes como o rei Davi, e que não contêm qualquer

13 Na mesma página citada, Guarinello sustenta que a identidade judaica manteve um caráter unitário, tanto étnico como religioso, no período do Império Romano. Esta, porém, é uma conclusão que vem sendo cada vez mais amplamente questionada. 
recriminação a tais relações. Uma grande tensão é deixada em evidência (GRUEN, 2016, p.95ss) ${ }^{14}$.

No contexto da conquista da terra de Canaã por parte dos ancestrais dos judeus, as fontes textuais asseveram que a preservação da identidade de Israel implicaria na aniquilação (o mandamento do herem, em hebraico, conforme Deuteronômio 7.2 e 20.17) ou expulsão dos povos que habitavam aquela terra (ÊExodo 23.23-33; Números 33.51-53). A justificativa tradicional para tal ação em textos posteriores foi de que os canaanitas teriam pecado e habitado numa terra que não lhes pertencia (BERTHELOT, 2011).

O conceito de eliminação e expulsão do "outro" recebeu novos contornos imaginários e simbólicos na nova situação político social no período do exílio e do Segundo Templo. Newsom (2011), se valendo dos conceitos de "eliminação", "dominação" e "assimilação" de Miroslav Volf, desenvolve as possibilidades de alternativas criativas encontradiças nos textos bíblicos posteriores de novos imaginários para dar sentido à realidade de submissão a dominadores estrangeiros. Estas concepções de "eliminação" e "dominação", oriundas do imaginário do Deus soberano de Israel, embora nunca tenham saído de cena, foram somadas a conceitos de "assimilação", e até mesmo "conluio", ao passo que também foram projetadas numa eliminação final de rivais em categorias simbólicas apocalípticas.

Diferentemente do ideal almejado de uma nação de Israel hermeticamente fechada em suas dimensões geográficas, cumprindo particularmente suas leis e cultuando seu Deus de acordo com seus preceitos, o cenário desse período posterior foi de subserviência a dominadores e convivência com outros dominados, com complexas implicações para a identidade judaica ${ }^{15}$.

A complexidade do tema pode ser constatada a partir dos nomes de identificação empregados no período correspondente. As várias possibilidades de nomes para identificar os antepassados que hoje chamamos de "judeus" tinham peso e conotações diferentes em distintos momentos, locais e situações, podendo ter mesmo prevalecido a dúvida e confusão em determinados momentos e locais. À situação peculiar dos judeus do período,

14 Newsom (2012) registra que há ampla evidência do surgimento de surpreendentes alternativas ao modelo deuteronômico de moralidade.

15 As fases da língua hebraica demonstram tanto a resistência em receber a linguagem estrangeira com o fim de preservar identidade própria, como também o inevitável intercâmbio com outras culturas e influência recebida (SAFRAI; STERN, 1976, p.1007ss; SÁENZ-BADILLOS, 1996; WILSON-WRIGHT, 2015). 
que era de (re)construção de fronteiras, eram intrínsecos a seletividade, fluidez, dinamismo e permeabilidade. Até mesmo as tradicionais concepções religiosas judaicas tidas como peculiares, como o monoteísmo, não eram tão monolíticas como tradicionalmente sempre foi pressuposto (RÖMER, 2016, p.205ss) ${ }^{16}$. Haja vista o debate recente sobre o conceito tradicional de sinagoga no mundo antigo, que rejeita incluir as "Guildas Ocupacionais" tendentes ao politeísmo, denominadas "sinagoga" por alguns autores antigos, que integravam membros judeus e de outras etnias (LAST, 2016).

No que se refere à visão "de dentro", isto é, a partir dos próprios judeus em relação à sua identidade perante os de fora, não é possível isolar uma postura de auto-identificação que fosse geral, que caracterizasse um posicionamento judaico único perante "os outros". Mas embora tenha existido grande variação no uso das palavras relativas, "judeu(s)", "hebreu(s)", "Israel" e outros derivados, isso não quer dizer que o conteúdo estava esvaziado, ou que os termos perderam completamente sua relação.

Dessa perspectiva interna, por um lado, o judaísmo era constituído de várias correntes antagônicas com tendências radicais na busca da afirmação da verdadeira identidade judaica (SILVA, 2006). Por outro lado, parece fazer sentido falar de um "judaísmo complexo" como proposto por Hengel e Deines (1995), como melhor alternativa diante dos conceitos antagônicos de "judaísmo comum" e "judaísmos". Neste caso, é possível considerar um judaísmo unificado da perspectiva da preservação contra os "de fora" em situações de conflito, o que teria incluído a busca constante por posturas viáveis a fim de, como uma nação, enfrentar as regras dos dominadores estrangeiros. Embora os irmãos briguem violentamente entre si, se unem para defender o lar contra os de fora. Estes "de fora", "outros", diga-se de passagem, são os que ameaçam, estão por perto, por isto são inimigos. Os "de longe" não são necessariamente inimigos. Os "gentios" são as "nações", mas num contexto de conflito são inimigos ${ }^{17}$.

16 Na concepção de identidade, considerando a época cristã tardia, as normas servem como parâmetros, mas não como regras rígidas intransponíveis. Isto quer dizer que a riqueza social aponta para o fato de que, ainda que se devam considerar os conflitos e intolerâncias resultantes da situação, entre o povo as identidades eram mais fluidas e as crenças perpassavam umas às outras (FUNARI, 2009a). Mesmo em época mais tardia, como no período da Inquisição no século XVI EC, o hibridismo de crenças pode ser percebido, notadamente em ambientes populares (GINZBURG, 1989).

17 Rosen-Zvi e Ophir (2018) argumentam que o termo hebraico "goyim”, tradicionalmente traduzido por "nações", recebeu o sentido de "gentios" por invenção de Paulo, o que 
Quanto à visão dos “de fora", isto é, como romanos e outros viam os judeus, no período referido existiam várias maneiras de estabelecer a identidade judaica de alguém ${ }^{18}$. Em situação complexa, em meio também à complexidade de uso dos termos, a relação conflituosa entre judeus e o Império Romano, especialmente as impactantes e trágicas revoltas, é um aspecto importante para melhor compreensão das questões de identidade (GOODMAN, 2011).

Esse período foi marcado por grandes revoltas judaicas: os Macabeus (167 a 164 aEC), e a Grande Revolta que levou à destruição de Jerusalém e do templo (66-73 EC), seguidas pelas revoltas de Kitos (115-117 EC), e Bar Kohba (132-135 EC). De modo geral, é possível afirmar que boa parte dessas revoltas foi motivada por conflitos internos, intra-judaicos, entrelaçadas por reações dos judeus contra o Império Romano (SILVA, 2006).

Neste ponto é preciso ressaltar que esses conflitos internos, intrajudaicos, incluíam as diferenças entre os próprios judeus quanto à relação com os outros, os de fora. Mais recentemente cresceu a tendência de admitir que a relação entre judeus e, especialmente, os gregos foi bem mais complexa e ambivalente do que um antagonismo simplista pode sugerir (GRUEN, 2011). A tradicional perseguição dos judeus atribuída simplisticamente a Antíoco IV, por exemplo, tem sido revista como resultado de algo complexo que atribui um papel mais preponderante ao conflito interno sobre a helenização (DORAN, 2011).

O período de Herodes o Grande foi marcado por uma relativamente boa relação entre os judeus e Roma. Com a morte do monarca, perto do início da EC, esta relação se deteriorou quando a disputa dos herdeiros de Herodes pelo trono levou o Imperador a instituir um governo direto na Judéia, incluindo Jerusalém. A presença do exército romano na cidade santa era entendida pelos judeus como profanação do solo sagrado, associada a

não corresponde ao sentido do termo na Bíblia Hebraica e no judaísmo antigo. Seria interessante aqui perguntar se as nuanças entre "nações" e "gentios", este último termo num sentido pejorativo, tem relação com nações distantes em geral e nações vizinhas, estas com o potencial de inimizade.

18 Goodman (2001) fala de cinco possibilidades: 1) a afirmação do próprio indivíduo de que era judeu seria suficiente em alguns casos; 2) alguma autoridade judaica poderia requerer para si o direito de definir a questão; 3) comunidades judaicas locais poderiam declarar quem eram seus membros; 4) não judeus de um local também poderiam reclamar o direito de definir quem era ou não judeu e 5) o Estado poderia selecionar os judeus da população em geral com interesses próprios. Além disso, é possível que tenha existido ainda alguma combinação de dois ou mais destes itens. 
frequentes ingerências nas tradições judaicas, somando ainda a insatisfação dos judeus contra seus próprios sacerdotes coniventes ao poder romano com seus altos impostos e constantes confiscos (STERN, 1974; SELVATICI, 2012).

Nesse período, dentre as várias nomenclaturas utilizadas ao longo do tempo, de modo geral, "Israel" era um termo interno principalmente como referência à nação ideal, e a identificação como "judeus" era utilizada pelos de fora. Este último termo era usado normalmente pelas autoridades romanas, provavelmente como continuação da referência à província persa aos arredores de Jerusalém com esse nome (SELTZER, 2005; GOODMAN, 2011).

Mas uma distinção mais evidente de quem era judeu aos olhos do governo romano se fez necessária com a instituição do fiscus judaicus, uma taxa obrigatória imposta a todos os judeus depois da revolta de 66-73 EC. Até mesmo a diferença entre judeus e cristãos, que não era clara antes da revolta, passa a receber contornos mais nítidos no final do século I EC em diante. Embora a igreja cristã tenha passado a se considerar o verdadeiro Israel, a distinção do judeu de fato era necessária diante da imposição da referida taxa por parte do Estado. Os próprios seguidores do Nazareno começaram a se desvencilhar dos laços identitários judaicos para se distanciar da hostilidade contra os judeus. Isso pode ser exemplificado pelo canônico evangelho de João, datado no final do século I EC, no qual os opositores de Jesus são os judeus - "os outros". Outro exemplo é o herege Marcião na primeira metade do século II EC, que radicalizou a separação entre Israel e Igreja rechaçando o Antigo Testamento cristão e tudo que com ele se aliava no Novo Testamento. A posição deste último, embora considerada herege, contribuiu para perpetuar a separação entre sinagoga e igreja (GOODMAN, 2011).

Resta também considerar os recentes retornos nos estudos judaicos à centralidade do conceito de tempo no judaísmo numa tendência diacrônica (GRIBETZ, 2019). Visto que "tempo" e "temporalidade" são considerados essenciais na concepção do judaísmo, é preciso perguntar pelas implicações para o estudo da identidade judaica a partir dos conceitos de tempo. O período em questão, por exemplo, implicou mudanças temporais significativas na trajetória do judaísmo que certamente tiveram consequências importantes para a identidade judaica a serem consideradas em estudos subsequentes.

\section{Qumran e a identidade judaica}

Portanto, a pesquisa sobre o mundo antigo que originou o ocidente obrigatoriamente passa pela história de Israel, que deu origem ao povo judeu 
e sua religião, comumente englobados no termo "judaísmo" - termo este campeão não só quando falamos dos judeus atualmente, mas também quando nos referimos ao período das origens de aproximadamente 200 aEC a 100 EC.

Esse período, tido como formativo para o judaísmo rabínico e cristianismo posteriores, é também o período, grosso modo, dos manuscritos do Mar Morto de Qumran, manuscritos considerados como a maior descoberta acadêmica do século XX. Independente do debate sobre a relação entre tais manuscritos e as ruínas de Qumran, o fato é que a descoberta deste material teve um impacto decisivo para novas concepções sobre o judaísmo desse período ${ }^{19}$.

Respeitados os limites das fontes qumrânicas, o fato é que hoje todos os manuscritos e fragmentos estão publicados. Depois de uma batalha tida como muito longa, envolvendo supostos atrasos nas publicações por razões as mais diversas e polêmicas, o público em geral tem acesso ao material, inclusive com os famosos manuscritos da caverna 1 disponíveis na internet (MACHADO; FUNARI, 2012).

Este novo quadro possibilita avançar para além das abordagens que focalizaram esses documentos como tais, e trabalhar com várias metodologias nas disciplinas das humanidades, não só na história e arqueologia, mas também na sociologia, antropologia, etc. Neste sentido, Qumran oferece fontes para estudos renovados a respeito da identidade no judaísmo antigo ${ }^{20}$.

Até então, as fontes básicas eram Josefo, Filo, o Novo Testamento cristão e deduções a partir do material deixado pelo judaísmo rabínico que foi constituído bem depois da destruição de Jerusalém e do templo em 70 EC. Os textos encontrados nas cavernas de Qumran foram fundamentais para colocar em xeque o judaísmo monolítico e unificado geralmente deduzido a partir daquelas fontes até então. Esses documentos acabaram por testemunhar um judaísmo muito mais diversificado do que aquele que se podia deduzir a partir das fontes rabínicas (GARCÍA MARTÍNEZ, 2006).

Em meio a essa diversificação, a relação do judaísmo com a apocalíptica, tendo em vista os textos de Qumran, é um dos campos de

19 Entretanto, esta constatação que tem sido afirmada de muitos modos, precisa ser devidamente dosada em relação aos limites das fontes qumrânicas. Stone (2010) alerta para o fato de que as descobertas de Qumran revelaram uma biblioteca, se assim podemos chamar, parcial e não completa, e que, mesmo em seu todo, seria apenas uma parte das fontes sobre o judaísmo antigo.

20 Um exemplo das várias possibilidades de abordagem está na obra editada por Grossman (2010). Já publicamos um livro sobre o tema desse artigo em relação a um conjunto específico dentre os manuscritos do Mar Morto (MACHADO, 2015). 
estudo que ganhou novo fôlego nos estudos acadêmicos, com importantes implicações para o tema da identidade. A profunda relação de Qumran com os temas apocalípticos é amplamente admitida a partir dos textos encontrados, tanto naqueles considerados originários do grupo qumrânico, como pela presença de cópias de obras do gênero apocalíptico, a ponto de que alguns cheguem a afirmar, com relutância de outros, que Qumran representa uma "comunidade apocalíptica". (COLLINS, 1997; KNIBB, 2010).

A relação de Qumran com a apocalíptica é muito importante, entre outras coisas, porque esta tem profundas implicações para a discussão recente sobre a identidade no judaísmo antigo. Nesta discussão, as diferenças em relação ao "outro" na apocalíptica podem ser colocadas em termos extremos, e este demonizado, ou amenizadas por uma visão mais inclusiva e complexa que vê a apocalíptica, incluindo Qumran, permeada por conceitos sapienciais mais associáveis com o outro.

No primeiro caso acima, os temas do dualismo, transcendência, teodiceia, e revelação divina peculiar que permeiam a apocalíptica de um modo racional teológico somam aos aspectos emotivos decorrentes da forte oposição e do completo pessimismo sobre a possibilidade de mudança do outro em razão da concepção de maldade intrínseca e imutável - não há acordos entre leões e cordeiros (DITOMMASO, 2011).

No segundo caso, a visão extrema que representa tendências teológicas recentes de exorcizar a apocalíptica da linguagem teológica, dada a resultante visão de mundo extremamente negativa, é vista como uma distorção histórica e hermenêutica apocalíptica unilateral. Há evidências de que o apocalipsismo e a sabedoria estavam entrelaçados no judaísmo antigo, do que certos textos qumrânicos são exemplo, como o 4QInstrução, que foi considerado uma obra sapiencial de instruções para a vida cotidiana com cosmovisão apocalíptica (FREYNE, 2011) ${ }^{21}$.

Uma tendência recente na academia é também destacar os apocalipses como literatura de resistência ao Império que está engajada em seu mundo urgindo a pregação de sua mensagem para convencer seus ouvintes. Neste caso, a literatura apocalíptica não representa tão somente uma fuga da realidade para a fantasia de pessoas que se escondem com medo de retaliação e rejeitam se engajar em seu mundo (PORTIER-YOUNG, 2011) ${ }^{22}$.

\footnotetext{
21 Ricoeur (1994) apresentou a apocalíptica como uma renovação radical que une os três grandes gêneros literários judaicos - a Torá, a Profecia e a Sabedoria.

22 Collins (2011) ressaltou a apocalíptica como resposta imaginativa a uma situação histórica e social específica.
} 
Entrementes, quanto a Qumran propriamente, a teoria “Qumranessênios" ainda é tida em alta conta entre os estudiosos até hoje. Porém, ao mesmo tempo, é amplamente admitido que esta teoria não pode mais ser sustentada nos mesmos moldes em que foi inicialmente apresentada pelos seus defensores nos primeiros anos, após a descoberta dos manuscritos e das cavernas em Qumran. A questão principal para isto é que cada vez mais vai sendo constatado que tal teoria era simplista demais, pois dependia basicamente da comparação com as dados de Josefo, que falou em três principais correntes judaicas no período: os fariseus, os saduceus e os essênios. Mas, como é mais bem percebido agora, como já enfatizado, o judaísmo do período era muito mais diversificado do que a divisão tripartite de Josefo (MACHADO, 2012) ${ }^{23}$.

No bojo da teoria "Qumran-essênios" está a questão da presença das mulheres no grupo. Uma conclusão amplamente aceita era de que se tratava de uma comunidade de homens celibatários, portanto, sem espaço para mulheres, conforme os relatos de Filo, Josefo e Plínio. Nos últimos anos, entretanto, tem ocorrido uma significativa mudança entre os estudiosos sobre as evidências dos manuscritos do Mar Morto quanto ao lugar da mulher na comunidade por trás desses textos (SCHULLER, 2019), o que certamente tem importantes implicações para a questão da identidade.

Em meio a tudo isso, permanece toda a discussão sobre a natureza do grupo que está por trás dos manuscritos encontrados e a melhor maneira de identificá-lo. Neste debate entram questões como se é apropriado ou não o emprego de termos como "comunidade", "seita", e assim por diante. Isso sem mencionar as teorias mais radicais, como a de Norman Golb, que consideram os textos qumrânicos completamente desassociados de qualquer grupo local, uma vez que tais teorias sustentam que esses textos foram trazidos de Jerusalém e depositados nas cavernas qumrânicas durante a fuga na Grande Revolta em 66-73 EC (MACHADO; FUNARI, 2012).

De qualquer forma, para falar de "comunidade" de Qumran é preciso fazê-lo de modo inclusivo, referindo-se a possivelmente várias comunidades que viveram nesse período em Qumran e nos arredores que, de um modo ou de outro, estavam relacionadas com o processo que deu origem aos textos encontrados nas cavernas (SWARUP, 2006, p.x).

23 Taylor (2010) oferece uma boa discussão sobre as possíveis relações dos manuscritos de Qumran com as fontes clássicas sobre os essênios. 
Seguindo esse raciocínio, então, é preciso dar uma palavra sobre as designações "seita", "comunidade" (alguns preferem o termo hebraico transliterado "Yahad" - "reunião", "congregação") ou "grupo", que são amplamente usadas de modos semelhantes ou diferentes por diversos autores que lidam com o tema. A importância disso está em que o emprego desses termos, cada um a seu modo, tende a pressupor conotações em relação ao lugar de Qumran no escopo do judaísmo do período que, naturalmente, tem implicações para o tema da identidade judaica.

O emprego da já tradicional expressão "comunidade de Qumran” foi seriamente questionada por Collins $(2010)^{24}$. Ele prefere falar de um movimento sectário com um grupo elitista que, conforme 1 QS 8, era composto de doze homens e três sacerdotes, cuja identificação do movimento como um todo com os essênios permanece plausível. Este movimento era marcado por uma associação dispersa em múltiplos assentamentos com características tipicamente sacerdotais, isto é, com práticas rituais de purificação - uma prática amplamente conhecida na antiguidade e que melhor explica o desproporcional número de tanques quadrados com escadas de acesso encontrados no sítio arqueológico de Qumran.

No campo da abordagem de Qumran em relação ao tema da identidade no âmbito do judaísmo antigo, têm crescido o número de trabalhos a partir de uma metodologia histórico sociológica, na qual está inserida a sociologia do sectarianismo, visto que o movimento qumrânico tem sido frequentemente chamado de "seita" desde 1948, mas não sem controvérsias. Esta abordagem histórico sociológica que dialoga com mestres mais antigos, como Max Weber e Ernst Troeltsch, e com os mais recentes Bryan Wilson, Rodney Stark e William Bainbrodge, estuda a identidade qumrânica a partir de teorias tipológicas, como mostra Jokiranta (2010).

No campo da inserção social do indivíduo, por exemplo, a teoria weberiana de "ansiedade da salvação" produzido pelo desejo de se demonstrar

24 Visto que esta expressão pressupõe um grupo residente em um local específico, Collins vê diversos problemas para o emprego dessa identificação: o Documento de Damasco e a Regra da Comunidade, dos quais várias cópias foram encontradas em Qumran, falam de múltiplos assentamentos. As significativas variantes textuais entre as cópias encontradas do mesmo documento podem ser indícios de que tais cópias não eram usadas na mesma comunidade. Além disso, não há qualquer referência a um só assentamento nos textos qumrânicos. Mais ainda, a dúvida sobre se o sítio de Qumran era um assentamento sectário quando os manuscritos foram depositados nas cavernas inibe qualquer abordagem do tema que dependa deste pressuposto. 
“eleito" pode ser empregada para melhor compreensão sociológica do determinismo qumrânico. Embora este determinismo qumrânico tenha dimensões próprias e ambíguas, o cultivo do estudo das Escrituras com ênfase em seu sentido preciso, a criação de nova literatura, e as leis rígidas, podem ser avaliados como elementos constitutivos da realidade qumrânica que contribuíram para a autoafirmação identitária do indivíduo como sujeito eleito.

No campo do recente conceito sociológico comunitário de seita como reação à sociedade externa pluralista, tal reação é entendida não como separação de uma ortodoxia prevalecente, mas como separação do mundo religioso pluralista que, em geral, prevalece. Em meio aos vários tipos de respostas religiosas a esse mal mundano um tanto amorfo e plural a partir da abordagem sociológica ${ }^{25}$, é possível se valer de tais respostas para euristicamente buscar melhor compreensão da identidade qumrânica. De fato, vários estudiosos tem identificado no corpus qumrânico diferentes respostas sectárias ao mal.

$\mathrm{Na}$ manutenção da identidade em meio a esse ambiente, além da resposta de isolamento geográfico, também outros meios de isolamento são empregados, como regras específicas sobre a associação com os de fora do grupo, vestimentas distintivas, modo distintivo de falar, endogamia e profissões particulares. Não é difícil perceber como esses elementos podem ser usados euristicamente no estudo dos documentos qumrânicos.

No afã sectário da separação em relação ao mundo, considerado irremediavelmente contaminado pelo mal, e anseio por uma nova sociedade, geralmente estão associados conceitos apocalípticos de fim do mundo, bem comuns em Qumran, em alguns casos com predições precisas sobre a data de tal acontecimento. A lógica disso é que, uma vez que o mundo está totalmente perdido, o próprio mal crônico mundano é sinal do escaton, isto é, do cumprimento do tempo final.

O que tornou esse tipo de concepção sectária encontradiça nos textos qumrânicos atrativo para certo nicho da sociedade judaica do período não se resume a uma resposta simples. Pode entrar na conta o desejo de um

25 Bryan Wilson enumera os "introversionistas" que buscam uma comunidade purificada, os "conversionistas" que buscam um "eu" transformado, os "manipulacionistas" que buscam uma percepção do mal transformada, os "taumaturgistas" que procuram dispensações específicas de milagres, os "reformistas" que querem reformar o mundo, os "revolucionistas" que buscam um mundo transformado diretamente por Deus, e os "utopistas" que procuram uma reconstrução do mundo através do próprio ser humano (JOKIRANTA, 2010, p.212-213). 
viver heroico na era dos macabeus (Weber), somado à insatisfação resultante dos desenvolvimentos que se deram no período pós-exílico. Entre as várias nuanças do conceito de "conversão" desenvolvidas por Rambo, Jokiranta, citada acima, acredita que os mais compatíveis com o caso de Qumran são a intensificação - renovado contato do convertido com sua fé anterior, a afiliação - transferência de pouco ou nenhum compromisso religioso para pleno envolvimento com uma instituição ou comunidade, e a transição institucional - mudança de uma tradição religiosa maior para alguma outra.

Essa abordagem sociológica exemplificada por Jokiranta acima, embora deva ser utilizada com cautela tendo em vista o grande risco de anacronismo e imposição das evidências, é útil porque teoriza o sectarianismo com conceitos que podem ajudar a entender melhor as imbricações identitárias qumrânicas.

Um elemento importante a ser considerado pela perspectiva sociológica é a já mencionada apocalíptica, no que diz respeito à integração social do indivíduo e do grupo perante a sociedade maior, tida como incuravelmente maculada pelo mal. Visto que há profundas relações dos textos qumrânicos com conceitos apocalípticos, como já foi mencionado acima, a abordagem dessa relação a partir de metodologias histórico sociológicas pode fornecer resultados muito animadores para melhor compreensão das questões identitárias inerentes.

Uma vez que o tema da previsão de um iminente fim do mundo, por exemplo, é praticamente inerente à apocalíptica ${ }^{26}$, com reações dos estudiosos em polos diferentes, como já mostrado acima, o estudo clássico de Festinger (1956) junto com as revisões deste trabalho (DAWSON, 1999) pode ser muito útil.

Muito mais do que a crença numa iminente destruição apocalíptica e redenção radical dos justos (os integrantes do grupo), as concepções sectárias apocalípticas do judaísmo antigo, nas quais se encaixam grupos como os essênios, incluindo o que está por trás dos textos qumrânicos, seja este considerado essênio ou não, incluíam um emaranhado de fatores de coesão do grupo.

26 No famoso debate, no campo da teologia, entre Käsemann (1983) e Bultmann (1983), respectivamente aluno e professor, o ponto central de discordância estava relacionado ao entendimento de que a apocalíptica, por definição, fixa o final cronologicamente. Enquanto aquele fala da apocalíptica como matriz da teologia cristã, este rejeita tal concepção, admitindo falar da escatologia como tal matriz, justamente por que esta não precisa fixar data para o fim do mundo. Bultmann representou a tentativa de levar a linguagem religiosa a sério, ao passo que teve em descrédito a cosmovisão que a apocalíptica representa, numa concepção completamente negativa desta (FREYNE, 2011). 
Ao passo que a pesquisa de Festinger e seus colegas foi resultado do trabalho bem específico relativo a um grupo que se manteve coeso e proselitista apesar de profecias não compridas anunciadas pela sua líder, tal empreendimento estimula o estudo sobre fatores de coesão ou mesmo coalizão de grupos apocalípticos. No caso dos estudos de Qumran, além das precauções quanto ao anacronismo, o foco não precisa ser necessariamente a continuidade da existência do grupo apesar do descumprimento de profecias propriamente, mas a demonstração do lugar da predição apocalíptica do escaton em meio aos fatores determinantes de coesão identitária do grupo.

Pelo menos no que diz respeito aos essênios, esse tipo de abordagem se torna ainda mais interessante tendo em vista o completo desaparecimento de referências a eles nas fontes antigas depois da Grande Revolta de 6673 EC. As possíveis respostas para um desaparecimento tão súbito, visto que fariseus e saduceus (os outros dois grandes grupos judaicos da famosa divisão tripartite do judaísmo antigo feita por Josefo) permanecem em evidência nos documentos, se tornam importante objeto de estudo para melhor compreensão da dinâmica identitária dos grupos judaicos do período (BURNS, 2006).

Nesse caso, entra na agenda também a utilidade de estudos comparativos com metodologias recentes (DETIENNE, 2004), pois se, por um lado, há a descontinuidade de grupos como Qumran e os essênios (pelo menos há ausência nas fontes posteriores), há a continuidade de outros, como o grupo dos nazarenos. Neste último caso, de certa perspectiva ${ }^{27}$, o messias crucificado pode representar uma profecia de reino messiânico iminente não cumprida, seguida de crescimento posterior da seita por proselitismo, a qual veio a se tornar depois uma das grandes religiões do mundo - o cristianismo.

Desta última perspectiva, as semelhanças e as diferenças razoáveis a serem consideradas podem fornecer melhores esclarecimentos pautados por uma metodologia comparativa.

\section{Considerações finais}

Ainda que seja necessário ter cuidados para não exagerar nas possibilidades, a descoberta dos manuscritos do Mar Morto inaugurou uma nova possibilidade de abordagem sobre o estudo das antiguidades,

27 Enquanto Schweitzer (2005, p.471ss), em seu famoso livro, desencorajou a busca do Jesus histórico que resulta, segundo ele, em profecia fracassada, Gager (1975, p.114ss) discutiu as razões sociológicas do sucesso do crescimento numérico do cristianismo. 
notoriamente sobre o judaísmo, mas também sobre o mundo no qual este estava inserido.

Um segundo momento importante é a publicação de todo material descoberto, que torna possível visualizar a verdadeira dimensão desse material, sua natureza fragmentada em relação ao todo que compunha, bem como seus limites quanto a esclarecer melhor os aspectos culturais da sociedade que está nas origens do mundo ocidental. Também faz com que as atenções outrora voltadas para a publicação em si dos manuscritos fiquem agora livres para buscar novos caminhos de abordagem desse material.

Mais do que fornecer material para o estudo da religião judaica antiga propriamente dita, essas fontes são importantes para compreender melhor as complexidades envolvidas nas identidades culturais, cuja pluralidade não se refere apenas às várias culturas diferentes, mas às agudas diferenças internas de uma mesma cultura, um mesmo povo, no caso, os judeus.

\section{Referências}

ALEXANDER, P. The Mystical Texts: Songs of the Sabbath Sacrifice and Related Manuscripts. London/New York: T \& T Clark, 2006.

APPIAH, K. A.; GATES, H. L. Identities. Chicago/London: The University of Chicago Press, 1995.

BERTELLI, A. R. (et. al. orgs.). Sociologia do Conhecimento. Rio de Janeiro: Zahar, 1974. BERTHELOT, K. The Original Sin of the Canaanites. In: HARLOW, D. C. (et. al. eds.). The "Other" in Second Temple Judaism. Essays in Honor of John J. Collins. Grand Rapids: Eerdmans, 2011, p.49-66.

BUltMAnN, R. Seria o Apocalipsismo a Matriz da Teologia Cristã? In: Apocalipsismo. São Leopoldo: Sinodal, 1983, p.255-261.

BURNS, J. E. Essene Sectarianism and Social Differenciation in Judaea After 70 C.E. Harvard Theological Review 99.3, p.247-27, 2006.

CHARlesworTh, J. H. (ed.). The Old Testament Pseudepigrapha. v.2. New York: Doubleday, 1985.

COLLINS, A. Y. Apocalypse Now: the State of Apocalyptic Studies Near the End of the First Decade of the Twenty-First Century. Harvard Theological Review 104.4, p.447-457, 2011.

COLLINS, J. J. Apocalypsism in the Dead Sea Scrolls. London: Routledge, 1997.

Sectarian Communities in the Dead Sea Scrolls. In: LIM, T. H.; COLLINS,

J. J. (eds.). The Oxford Handbook of The Dead Sea Scrolls. Oxford: Oxford University Press, 2010, p.151-172. 
DAWSON, L. L. When Prophecy Fails and Faith Persists: A Theoretical Overwiew. Nova Religio. The Journal of Alternative and Emergent Religion 3.1, p.60-82, 1999.

DETIENNE, M. Comparar o Incomparável. Aparecida: Ideias e Letras, 2004.

DITOMMASO, L. The Apocaliptic Other. In: HARLOW, D. C. (et. al. eds.). The "Other" in Second Temple Judaism. Essays in Honor of John J. Collins. Grand Rapids: Eerdmans, 2011, p. 221-246.

DORAN, R. The Persecution of Judeans by Antiochus IV: The Significance of "Ancestral Laws". In: HARLOW, D. C. (et. al. eds.). The "Other" in Second Temple Judaism. Essays in Honor of John J. Collins. Grand Rapids: Eerdmans, 2011, p. 423-433.

FESTINGER, L.(et. al.). When Prophecy Fails. A social and psychological study of a modern group that predicted the destruction of the world. New York: Harper \& Row, 1956.

FREYNE, S. Apocalipticism as Rejected Other: Wisdom and Apocalypticism in Early Judaism and Early Christianity. In: HARLOW, D. C. (et. al. eds.). The "Other" in Second Temple Judaism. Essays in Honor of John J. Collins. Grand Rapids: Eerdmans, 2011, p. 247-261.

FUNARI, P. P. A. (et. al. orgs.). Identidades, discurso e poder: Estudos da arqueologia contemporânea. São Paulo: FAPESP/Annablume, 2005.

FUNARI, P. P. A. Arqueologia e patrimônio. Erechim: Habilis, 2007.

FUNARI, P. P. A. (et. al. orgs.). New Perspectives on the Ancient World. Modern Perceptions, Ancient Representations. Oxford: Archeopress, 2008.

FUNARI, P. P. A. (et. al. orgs.). Política e Identidades no Mundo Antigo. São Paulo: FAPESP/Annablume, 2009.

FUNARI, P. P. A. Gregos. In: FUNARI, P. P. A. (Org.). Religiões que o mundo perdeu. São Paulo: Contexto, 2009a, p. 41-52.

GAGER, J. G. Kingdom and Community. The Social World of Early Christianity. New Jersey: Prentice-Hall, 1975.

GARCÍA-MARTÍNEZ, F. Textos de Qumran. Petrópolis: Vozes, 1995.

Qumran en el Siglo XXI. Cambios y Perspectivas Después de 50

Años de Estudios. MEAH, sección Hebreo 55, p.309-334, 2006.

GINZBURG, C. O Queijo e os Vermes. O cotidiano das ideias de um moleiro perseguido pela Inquisição. São Paulo: Companhia das Letras, 1989.

GOODMAN, M. Identity and Authority in Ancient Judaism. Judaism 39, p.192-201, 2001.

Romans, Jews, and Christians on the Names of the Jews. In: HARLOW,

D. C. (et. al. eds.). The "Other" in Second Temple Judaism. Essays in Honor of John J. Collins. Grand Rapids: Eerdmans, 2011, p.391-401.

GRIBETZ, S. K. The Temporal Turn in Ancient Judaism and Jewish Studies. Currents in Biblical Research 17.3, p.332-395, 2019.

GRILLO, J. G. C.; FUNARI, P. P. A. Antiguidade Clássica: Grécia. In: VENTURINI, R. L. B. (org.). História Antiga I: fontes e métodos. Maringá: Eduem, 2010. 
GROSSMAN, M. L. (ed.). Rediscovering the Dead Sea Scrolls. An Assessment of Old and New Approaches and Methods. Grand Rapids: Eerdmans, 2010.

GRUEN, E. S. Jews and Greeks as Philosphers: A Challenge to Otherness. In: HARLOW, D. C. (et. al. eds.). The "Other" in Second Temple Judaism. Essays in Honor of John J. Collins. Grand Rapids: Eerdmans, 2011, p.402-422.

The Construct of Identity in Hellenistic Judaism. Essays on Early Jewish Literature and History. Berlin: De Gruyter, 2016.

GUARINELLO, N. L. Império Romano e Identidade Grega. In: FUNARI, P. P. A.; SILVA, M. A. O. (orgs.). Política e Identidades no Mundo Antigo. São Paulo: FAPESP/Annablume, 2009, p.147-161.

HENGEL, M.; DEINES, R. E. P. Sanders' "Common Judaism," Jesus, and the Pharisees: Review Article of "Jewish Law from Jesus to the Mishnah" and "Judaism: Practice and Belief" by E. P. Sanders. The Journal of Theological Studies 46.1, p.1-41, 1995.

HimmelfarB, M. Ascent to Heaven in Jewish \& Chritian Apocalypses. New York/ Oxford: Oxford University Press, 1993.

KÄSEMANN, E. Os Inícios da Teologia Cristã. In: Apocalipsismo. São Leopoldo: Sinodal, 1983, p.231-251.

KNIBB, M. A. Apocalypticism amd Messianism. In: LIM, T. H.; COLLINS, J. J. (eds.). The Oxford Handbook of The Dead Sea Scrolls. Oxford: Oxford University Press, 2010, p.403-432.

KÜNG, H. Ser Cristão. Rio de Janeiro: Imago, 1976.

JOKIRANTA, J. Sociological Approaches to Qumran Sectarianism. In: LIM, T. H.; COLLINS, J. J. (eds.). The Oxford Handbook of The Dead Sea Scrolls. Oxford: Oxford University Press, 2010, p.200-231.

JONES, S. Categorias históricas e a práxis da identidade: a interpretação da etnicidade na arqueologia histórica. In: FUNARI, P. P. A. (et. al. orgs.). Identidades, discurso e poder: Estudos da arqueologia contemporânea. São Paulo: FAPESP/Annablume, 2005, p.27-43.

LAST, R. The Other Synagogues. Journal for the Study of Judaism 47, p.330-363, 2016.

LIEU, J. "Impregnable Ramparts and Walls Of Iron": Boundary and Identity in Early "Judaism and Christianity". New Testament Studies 48, p.297-313, 2002.

MACHADO, J.. Perspectivas da Hipótese Qumran-Essênios. A propósito de um livro de Gabrielle Boccaccini. Estudos de Religião 26.42, p.238-261, 2012.

Anjos, Sacerdotes e Místicos. Identidade e Sectarismo nos Cânticos do Sacrifício Sabático dos Manuscritos do Mar Morto. São Paulo: Annablume/FAPESP, 2015.

MACHADO, J.; FUNARI, P. P. A. Os Manuscritos do Mar Morto. Uma Introdução Atualizada. São Paulo: Annablume, 2012.

NEWSOM, C. A. God's Other: The Intractable Problem of the Gentile King in Judaean and Early Jewish Literature. In: HARLOW, D. C. (et. al. eds.). The “Other" in Second Temple Judaism. Essays in Honor of John J. Collins. Grand Rapids: Eerdmans, 2011, p.31-48. 
Models of the Moral Self: Hebrew Bible and Second Temple Judaism. Journal of Biblical Literature 131.1, p.5-25, 2012.

NICKELSBURG, G. W. The We and Other in the Worldview of 1 Enoch, the Dead Sea Scrolls, and Other Early Jewish Texts. In: HARLOW, D. C. (et. al. eds.). The "Other" in Second Temple Judaism. Essays in Honor of John J. Collins. Grand Rapids: Eerdmans, 2011, p.262-278.

PELEGRINI, S. C. A.; FUNARI, P. P. A. O que é Patrimônio Cultural Imaterial. São Paulo: Brasiliense, 2008.

PORTIER-YOUNG, A. E. Apocalypse Against Empire. Theologies of Resistance in Early Judaism. Grand Rapids: Eerdmans, 2011.

RAGO, M.; FUNARI, P. P. A. (orgs.). Subjetividades antigas e modernas. São Paulo: Annablume, 2008.

RICOEUR, P. Le Conflit des Intérpretations. Essais d’Herméneutique. Paris: Seuil, 1969.

Temps et récit III, Le temps raconté. Paris: Seuil, 1985.

. Soi-même comme um autre. Paris: Seuil, 1990.

. Lectures 3. Paris: Seuil, p.312-321, 1994.

ROBBINS, V. K. The Tapestry of Early Christian Discourse: Rhetoric, society and ideology. London/New York: Routledge, 1996.

Exploring the Texture of Texts: A guide to socio-rhetorical interpretation. Harrisburg: Trinity Press International, 1996.

RÖMER, T. A Origem de Javé. O Deus de Israel e seu Nome. São Paulo: Paulus, 2016.

ROSEN-ZVI, I.; OPHIR, A. Paul and the Invention of the Gentiles. The Jewish Quarterly Review 106.1, p.1-41, 2015.

SÁENZ-BADILLOS, A. A History of Hebrew Language. Cambridge: Cambridge University Press, 1996.

SAFRAI, S.; STERN, M. (eds.). The Jewish People in the First Century. 2 vol. Philadelphia: Fortress Press, 1976.

SCHULLER, E. M. Did/Could Women Pray the Qumran Thanksgiving Psalms? The Catholic Biblical Quarterly 81, p.1-15, 2019.

SCHWEITZER, A. A Busca do Jesus Histórico. São Paulo: Novo Século, 2005.

SELVATICI, M. As Relações entre Judeus Palestinos e o Poder Romano nos Séculos I A.C. - I D.C. In: CARLAN, C. U. (et. al. eds.). História Militar do Mundo Antigo 3. Guerras e Culturas. São Paulo: Annablume, 2012, p.133-148.

SELTZER, R. M. Jewish People. In: JONES, L. (ed.). Encyclopedia of Religion. Second Edition. Farmington Hills: Thompson Gale, 2005, p.4854-4865.

SILBERSTEIN, L. J. Mapping, Not Tracing: Openning Reflection. In: SILBERSTEIN, L. J. (ed.). Mapping Jewish Identities. New York/London: New York University Press, 2000, p.1-36. 
SILVA, R. M. S. Pluralidade e Conflito. As Revoltas Judaicas e a Ideologia do Poder. Uma História Comparada das Guerras Judaicas entre os sec. II a.E.C. e I E.C. 2006. 213 f. Dissertação (Mestrado em História). UFRJ. Rio de Janeiro, RJ.

SILVA, C. F. O Caminho para o Deserto. Origem e formação da comunidade de Qumran segunda análise histórica do Documento de Damasco e do Rolo das Regras. São Paulo: FAPESP/Humanitas, 2016.

STERN, M. The Province of Judaea. In: SAFRAI, S.; STERN, M. (eds.). The Jewish People in the First Century. Philadelphia: Fortress Press, 1974, p.308-376.

STONE, M. E. The Scrolls and the Literary Landscape of Second Temple Judaism. In: HEMPEL, C. (ed.). The Dead Sea Scrolls: Text and Context. Leiden \& Boston: Brill, 2010, p.15-33.

2011.

Ancient Judaism. New Visions and Views. Grand Rapids: Eerdmans,

SWARUP, P. The Self-Undestanding of the Dead Sea Scrolls Community. An Eternal Planting. A House of Holiness. London: T \& T Clark, 2006.

TAYLOR, J. E. The Classical Sources on the Essenes and the Scrolls Communities. In: LIM, T. H.; COLLINS, J. J. (eds.). The Oxford Handbook of The Dead Sea Scrolls. Oxford: Oxford University Press, 2010, p.173-199.

TOBOLOWSKY, A. Israelite and Judahite History in Contemporary Theoretical Approaches. Currents in Biblical Research 17.1, p.33-58, 2018.

VERMÈS, G. Os Manuscritos do Mar Morto. $4^{\text {a }}$ ed. rev. e ampl. São Paulo: Mercúrio, 1997.

VIER, F. (ed.). Compêndio do Vaticano II. Constituições, decretos, declarações. Petrópolis: Vozes, 1968.

WILSON-WRIGHT, A. From Persepolis to Jerusalem. A Reevaluation of Old Persian-Hebrew Contact in the Archaemenid Period. Vetus Testamentum 65, p.152-167, 2015.

WITHERINGTON, B. A Cristologia de Jesus Revista. In: BECKWITH, F. J. (et. al. eds.). Ensaios Apologéticos. São Paulo: Hagnos, 2006.

Submetido em: 8-6-2019

Aceito em: 13-4-2020 